\title{
Identifying permethrin resistance loci in malaria vectors by genetic mapping
}

\author{
CLAUDIA WITZIG ${ }^{1}$, CHARLES S. WONDJI ${ }^{1}$, CLARE STRODE ${ }^{1}$, \\ ROUSSEAU DJOUAKA ${ }^{2}$ and HILARY RANSON ${ }^{1} *$ \\ ${ }^{1}$ Liverpool School of Tropical Medicine, Pembroke Place, Liverpool L3 5QA, UK \\ ${ }^{2}$ International Institute for Tropical Agriculture, Cotonou, Benin
}

(Received 7 November 2012; revised 5 December 2012 and 2 Fanuary 2013; accepted 3 Fanuary 2013; first published online 28 February 2013)

SUMMARY

Identification of the major loci responsible for insecticide resistance in malaria vectors would aid the development and implementation of effective resistance management strategies, which are urgently needed to tackle the growing threat posed by resistance to the limited insecticides available for malaria control. Genome-wide association studies in the major malaria vector, Anopheles gambiae, have been hindered by the high degree of within-population structuring and very low levels of linkage disequilibrium hence we revisited the use of quantitative trait loci (QTL) mapping to study resistance phenotypes in this vector species. Earlier work, identified two major QTL associated with pyrethroid resistance in A. gambiae s.s. from East Africa using genetic crossing of laboratory-colonized resistant and susceptible strains. In this study, we report the results from genetic mapping of pyrethroid resistance in three isofemale pedigrees established from wild-caught female A. gambiae s.s. mosquitoes from Benin. We identified two QTL on chromosomes $2 \mathrm{~L}$ and $3 \mathrm{R}$ in these field populations, in similar genomic locations to the QTL identified in laboratory strains. The relative merits of two alternative study designs are discussed and suggestions made for future genetic mapping studies of insecticide resistance in mosquitoes.

Key words: Anopheles gambiae, natural pedigrees, QTL, malaria, insecticide resistance.

\section{INTRODUCTION}

Despite extensive control efforts, over half the world's population remain at risk of malaria and the disease has a massive impact on health and economic development, particularly in Africa (WHO, 2011). The main vector control methods, indoor residual spraying (IRS) and insecticide-treated bed nets (ITNs), rely on insecticides but resistance to the limited number of available insecticides is developing rapidly, with some populations now showing resistance to all four classes (Ranson et al. 2009; Constant et al. 2012). Resistance to pyrethroid insecticides is of greatest concern as these are the major class of insecticides used in public health and the only insecticide class permitted for impregnation of mosquito nets (WHO, 2012). If pyrethroid insecticides were to fail due to resistance of target populations, WHO estimates a loss of $\sim 50 \%$ of the current impact on vector control in Africa (WHO, 2012).

Attempts to identify the genetic basis of pyrethroid resistance in malaria vectors have focused largely on genotyping for known target site mutations and/or comparing transcript levels in insecticide-resistant and -susceptible populations using microarrays. Two alternative amino acid substitutions in the Anopheles gambiae voltage-gated sodium channel, L1014F and

* Corresponding author: Department of Vector Biology, Liverpool School of Tropical Medicine, Pembroke Place, Liverpool L3 5QA, UK. Tel: + 44151705 2525. Fax: + 44 151705 3369. E-mail: hranson@liverpool.ac.uk
L1014S, have been clearly associated with resistance to pyrethroids (Martinez-Torres et al. 1998; Ranson et al. 2000a; Reimer et al. 2008). However, the recent identification of an additional mutation (N1575Y), in a distinct part of the sodium channel protein which confers additional protection against insecticide exposure (Jones et al. 2012), highlights the potential pitfalls of relying on screening single loci. Gene expression microarray-based approaches in $A$. gambiae have evolved from small custom-made arrays containing probes for gene families associated with insecticide detoxification (David et al. 2005) to whole genome arrays (Mitchell et al. 2012). These approaches have successfully identified overexpressed candidates, several of which have subsequently been shown to metabolize pyrethroids (Müller et al. 2008; Stevenson et al. 2011; Mitchell et al. 2012). However microarray data sets do not lead directly to the identification of resistance-associated polymorphisms in DNA and extensive follow-up work is often required to identify these loci.

The sequencing of the $A$. gambiae genome (Holt et al. 2002; Lawniczak et al. 2010) has identified a large number of single nucleotide polymorphisms (SNPs) which have enabled association-mapping techniques to be applied to identify resistance loci. As with the microarray-based approaches, these studies initially relied on using SNPs within, or in the vicinity, of known candidate loci (Weetman et al. 2010) but more recently have progressed to genomewide association studies (GWAS). However, the low

Parasitology (2013), 140, 1468-1477. C Cambridge University Press 2013. The online version of this article is published within an Open Access environment subject to the conditions of the Creative Commons Attribution-NonCommercial-ShareAlike licence $<$ http://creativecommons.org/licenses/ by-nc-sa/3.0/>. The written permission of Cambridge University Press must be obtained for commercial re-use. 
levels of linkage disequilibrium and high levels of population substructuring (Neafsey et al. 2010; Weetman et al. 2010), have limited the utility of these approaches in A. gambiae and efforts are now being directed to using next generation sequencing to study this trait (Weetman, Neafsey and Donnelly, personal communication).

Early studies using genetic mapping to identify insecticide resistance-associated loci were reliant on morphological markers. In the 1960s, DDT resistance was reported to be a monofactorial trait in several insect species and linked to the brown body marker in the housefly, Musca domestica (Milani, 1963). In the 1990s, genetic evidence of close association between the $k d r$ phenotype and the voltage-gated sodium channel was established (Williamson et al. 1993; Knipple et al. 1994). The genetic basis of non-target site resistance has proved less tractable to study. Studies in the housefly identified up to nine individual resistance loci, controlling traits such as insecticide metabolism and penetration. The co-localization of the majority of these on a single chromosome led to the suggestion that there is a major regulatory locus that controls multiple resistance mechanisms (Plapp, 1976). Genetic linkage maps greatly improved with the advent of techniques for screening molecular markers such as microsatellites and Restriction Fragment Length Polymorphisms (RFLP) (Heckel, 1993). This facilitated the resolution of quantitative trait loci (QTL) controlling polygenic traits.

The first QTL to be identified in A. gambiae, were associated with refractoriness to Plasmodium parasites (Zheng et al. 1997). Later, similar approaches were used to identify QTL associated with permethrin or DD'T resistance in laboratory strains of $A$. gambiae (Ranson et al. 2000b, 2004), Anopheles funestus (Wondji et al. 2007b), Anopheles arabiensis (Witzig et al. 2013) and Aedes aegypti (Saavedra-Rodriguez et al. 2008). These studies have in common, that they used experimental crosses between a resistant and a susceptible population to generate mapping populations. However, it is not clear whether the loci identified in laboratory-colonized strains are truly representative of those found in natural populations. In an alternative approach, natural pedigrees, collected from field-caught females, are used to map allelic variants affecting parasite development (Niare et al. 2002; Riehle et al. 2006). Here we have adopted the latter approach to map the major QTL associated with resistance to permethrin in $A$. gambiae in West Africa.

Benin was chosen as a study site due to the high level of pyrethroid resistance in the south of the country (Djègbè et al. 2011) where $A$. gambiae s.s. is the major malaria vector. A microarray gene expression study on a permethrin resistant population from Akron, an urban agricultural site on the outskirts of the capital city Porto-Novo, identified several candidate genes associated with resistance (Djouaka et al. 2008). These included the cytochrome P450s $C y p 6 p 3$ and $C y p 6 m 2$ that have previously been associated with pyrethroid resistance (Müller et al. 2008; Stevenson et al. 2011) and two cuticular precursor genes ( $C p l c g 3$ and $C p l c g 4)$. These cuticular genes were also found to be overexpressed in permethrin resistant $A$. gambiae samples from neighbouring Nigeria (Awolola et al. 2009). The 1014F kdr allele is also found at a high frequency of $>86 \%$ in A.gambiae s.s. from this area (Yadouleton et al. 2010).

\section{MATERIALS AND METHODS}

\section{Field collections and molecular characterization}

Gravid or blood-fed A. gambiae s.l. adult females resting indoors were collected in houses in Akron, Porto-Novo, Benin (lat: 4.4300; long: 2.6400) between 6-8 am or during the night from 12 midnight to 6 am in September 2009. Live Anopheles mosquitoes were transferred to cages and blood fed on two or three subsequent nights on live guinea pigs to ensure all females could feed to satiation. Four to six days after blood feeding individual gravid females were transferred into $1.5 \mathrm{ml}$ Eppendorf tubes for egg laying (Morgan et al. 2010). After oviposition the females $\left(\mathrm{F}_{0}\right)$ were separated from eggs and stored over silica gel for later molecular analysis. Eggs were transported to the Liverpool School of Tropical Medicine, and families were raised to adults separately.

Field-collected females were morphologically identified as belonging to the $A$. gambiae species complex according to the key of (Gillies and de Meillon, 1968) and identified as A. gambiae s.s. M-form by PCR (Santolamazza et al. 2008). $\mathrm{F}_{1}$ progeny from individual isofemale lines were inbred to form an $\mathrm{F}_{2}$ generation which was then phenotyped for permethrin resistance as described below.

DNA was extracted from the parental females $\left(\mathrm{F}_{0}\right)$ eight $F_{1}$ progeny from each family (four males, four females), and all $F_{2}$ progeny using the LIVAK method (Collins et al. 1987). The $\mathrm{F}_{0}$ and $\mathrm{F}_{1}$ individuals were genotyped for the $1014 \mathrm{~F} / \mathrm{S} k d r$ and 119S ace-1 (mutation in the sequence for acetylcholinesterase conferring target-site resistance to carbamate insecticides) alleles using a pyrosequencing assay (Witzig et al. 2013). The $k d r$ genotype was additionally confirmed through sequence analysis for the three parental females. Karyotypes for the 2La inversion (White et al. 2007) and the $2 \mathrm{Rb}$ inversions (Lobo et al. 2010) were determined by PCR for each family in $F_{0}$, eight $F_{1}$ samples and, for 2La only, in all $\mathrm{F}_{2}$ offspring.

\section{Insecticide susceptibility assays}

To assess the resistance profile of the Akron population, adults (2-5 days old) reared from 
field-collected larvae were exposed to permethrin $(0 \cdot 75 \%)$, bendiocarb $(0 \cdot 1 \%)$ or DDT $(4 \%)$ for one hour. Insecticide susceptibility assays were carried out following the WHO protocol (WHO, 1998). Mortality was determined after $24 \mathrm{~h}$; lower and upper limits of CI 95\% were calculated using VassarStats (Lowry, 2004). Dead and alive individuals were counted and stored separately over silica gel for DNA extraction.

For resistance phenotyping of $\mathrm{F}_{2}$ offspring, 1-3 day old male and female $F_{2}$ progeny of three families were exposed to $0 \cdot 75 \%$ permethrin (family 17 ) or $2 \%$ permethrin (families 15 and 25 , due to their low mortality in initial bioassays with $0.75 \%$ permethrin) for one hour and scored as dead or alive $24 \mathrm{~h}$ after exposure and kept on silica gel for further molecular analysis.

\section{Genotyping of mapping families}

A subset of previously described microsatellite markers (Zheng et al. 1996; Ranson et al. 2004; Witzig et al. 2013) were selected to include markers on each chromosome arm. Microsatellite loci were initially screened using a tailed primer system described by (Oetting et al. 1998). Primer pairs for informative markers (Table 1 and S1 - the latter in Online version only) were re-synthesized to directly incorporate a fluorescent dye (WellRed oligos, Sigma-Aldrich). Each PCR was made by mixing $11 \mu \mathrm{ldd} \mathrm{H}_{2} \mathrm{O}, 1.5 \mu \mathrm{l} 10 \times$ Taq buffer $\left(1.5 \mathrm{~mm} \mathrm{MgCl}_{2}\right)$, $0 \cdot 3 \mu \mathrm{l}$ of $10 \mathrm{mM}$ dNTPs, $0 \cdot 3 \mu \mathrm{l}$ of $25 \mathrm{mM} \mathrm{MgCl}_{2}, 0 \cdot 5 \mu \mathrm{l}$ each of $10 \mathrm{~mm}$ site specific forward and reverse primer, $0 \cdot 12 \mu \mathrm{l}$ of Taq Polymerase and $1 \mu \mathrm{l}$ of gDNA to a final volume of $15 \mu \mathrm{l}$. Cycling conditions were: $95^{\circ} \mathrm{C} / 5 \mathrm{~min} ; \quad\left(95^{\circ} \mathrm{C} / 45 \mathrm{~s} ; 57^{\circ} \mathrm{C} / 45 \mathrm{~s} ; 72^{\circ} \mathrm{C} /\right.$ $45 \mathrm{~s}$ ) for 35 cycles; $72^{\circ} \mathrm{C} / 10 \mathrm{~min}$. PCR products of up to three loci were combined and fragment analysis was performed on a CEQ ${ }^{\mathrm{TM}} 8000$ (Beckman Coulter, Inc., USA). Microsatellite genotypes were scored using the GenomeLab GeXP software (version 10.0.9; Beckman Coulter).

Three SNP markers (one on 2R, and two on 3R) were identified by de novo sequence analysis using the primers shown in Table S1 - in Online version only. Pyrosequencing assays were designed to score SNPs in each of these genes (AGAP002865, AGAP008212 and AGAP008447) (Table S2 - in Online version only). In addition, the $1014 k d r$ genotype in the $\mathrm{F}_{2}$ progeny was determined by pyrosequencing as described previously (Wondji et al. 2007a; Witzig et al. 2013).

\section{Marker data analysis, linkage mapping and LOD scoring}

Associations between genotypes at each locus and the resistance phenotype (dead or alive) were assessed.
Single marker analysis was performed for each family to test for association $(P \leqslant 0 \cdot 05)$ between genotype and resistance phenotype using Haploview 4.2 (Barrett et al. 2005). The JoinMap 2.0 software package (Stam and van Ooijen, 1996) was used to build genetic linkage maps for each family. Data from linkage maps along with the genotype/phenotype data were entered into Windows QTL Cartographer 2.5 (Wang et al. 2005) and interval mapping (IM) (Lander and Botstein, 1989; Jansen, 1993), composite interval mapping (CIM) (Zeng, 1993) and multiple interval mapping (MIM) (Kao et al. 1999) procedures were performed for each family separately and for the combined data.

MIM uses multiple marker intervals simultaneously to fit multiple putative QTL directly in the model for mapping QTL. For MIM an initial model was created by forward and backward markers selection with a significance level of $0 \cdot 05$. The model was refined by optimizing QTL positions, searching for new and testing for existing QTLs.

RESULTS

\section{Insecticide susceptibility assays}

Insecticide bioassays confirmed the presence of DDT and permethrin resistance in the A. gambiae s.l. Akron population but full susceptibility to bendiocarb. Twenty four hour mortality in adults raised from field-collected larvae was 52\% $(n=82$, CI 95\% lower limit 0.41, upper limit $0 \cdot 63)$ to permethrin, $0 \%$ to DDT $(n=60$, CI $95 \%$ lower limit 0 , upper limit 0.075$)$ and $100 \%$ to bendiocarb ( $n=96$, CI 95\% lower limit 0.95, upper limit 1).

A total of 109 females were collected and 59\% (64 females) laid eggs. Forty seven of these egg batches were fertile (hatching rate $73 \%$ ). The progeny of 21 families were kept as separate families of approximately $15-40 \quad \mathrm{~F}_{1}$ individuals. The $1014 \mathrm{~F}$ $k d r$ frequency in wild-caught females was 0.92 ( $n=74$, CI 95\% lower limit 0.86, upper limit 0.96). All females were M form and neither the G119S ace-1 mutation in the gene for acetylcholinesterase nor the $1014 \mathrm{~S}$ or $1575 \mathrm{Y}$ mutations in the voltage-gated sodium channel (Ranson et al. 2000a; Jones et al. 2012) were detected.

Only three of the 21 families produced sufficient $\mathrm{F}_{2}$ progeny for phenotyping. This drop in progeny numbers from $F_{1}$ to $F_{2}$ highlights the difficulties in colonizing wild-caught $A$. gambiae and, as discussed below, is an important limitation of the natural pedigree approach. All three families showed strong permethrin resistance. Families 15 and 25 were initially phenotyped using $0.75 \%$ permethrin (the WHO diagnostic dose) but $100 \%$ survived a one hour exposure and mortality rates ranging from $5 \cdot 3 \%$ to $20 \%$ mortality were obtained after $90 \mathrm{~min}$. Using a 
Table 1. Details of microsatellite and SNP markers used for genotyping the $\mathrm{F}_{2}$ progeny of families 15 , 17 and 25 including the physical distances in Mb according to VectorBase, http://www.vectorbase.org, A. gambiae PEST annotation, AgamP3.5 (Megy et al. 2012), and allele size range

\begin{tabular}{|c|c|c|c|c|c|c|c|}
\hline & Marker & Source & $\begin{array}{l}\text { Location }^{\mathrm{a}} \\
\text { (Mb) }\end{array}$ & $\begin{array}{l}\text { Allele size } \\
\text { range (bp) }\end{array}$ & 15 & 17 & 25 \\
\hline \multirow[t]{2}{*}{ X chromosome } & 53 & 1 & $3 \cdot 6$ & $87-97$ & & $\mathrm{x}$ & \\
\hline & 80 & 1 & $7 \cdot 0$ & 80-108 & & $\mathrm{x}$ & \\
\hline Chromosome 2 & 46 & 1 & $1 \cdot 2$ & $133-142$ & & & $\mathrm{x}$ \\
\hline \multirow[t]{8}{*}{$2 \mathrm{R}$} & 803 & 1 & $1 \cdot 9$ & $144-146$ & $\mathrm{x}$ & $\mathrm{x}$ & \\
\hline & 197 & 1 & $10 \cdot 4$ & 83-96 & $\mathrm{x}$ & $\mathrm{x}$ & \\
\hline & 757 & 1 & $14 \cdot 7$ & 79-101 & $\mathrm{x}$ & $\mathrm{x}$ & $\mathrm{x}$ \\
\hline & 799 & 1 & $24 \cdot 9$ & 74-93 & & & $\mathrm{x}$ \\
\hline & 2R_si_5 & 3 & $28 \cdot 5$ & $246-256$ & $\mathrm{x}$ & $\mathrm{x}$ & $\mathrm{x}$ \\
\hline & SNP1 ${ }^{b}$ & & $28 \cdot 5$ & & $\mathrm{x}$ & $\mathrm{x}$ & $\mathrm{x}$ \\
\hline & 770 & 1 & $40 \cdot 4$ & $174-188$ & & $\mathrm{x}$ & $\mathrm{x}$ \\
\hline & 117 & 1 & $42 \cdot 7$ & $116-123$ & & $\mathrm{x}$ & $\mathrm{x}$ \\
\hline \multirow[t]{6}{*}{$2 \mathrm{~L}$} & $k d r^{\mathrm{b}}$ & & $24 \cdot 2$ & & & $\mathrm{x}$ & \\
\hline & 637 & 1 & $25 \cdot 5$ & $102-105$ & $\mathrm{x}$ & & \\
\hline & 787 & 1 & $26 \cdot 8$ & $131-135$ & & $\mathrm{x}$ & $\mathrm{x}$ \\
\hline & 772 & 1 & $42 \cdot 0$ & $131-152$ & & & $\mathrm{x}$ \\
\hline & 603 & 1 & $42 \cdot 0$ & $105-109$ & & $\mathrm{x}$ & \\
\hline & 675 & 1 & $46 \cdot 9$ & $101-114$ & $\mathrm{x}$ & & $\mathrm{x}$ \\
\hline Chromosome 3 & 776 & 1 & $2 \cdot 5$ & 87-102 & $\mathrm{x}$ & $\mathrm{x}$ & $\mathrm{x}$ \\
\hline \multirow[t]{16}{*}{$3 \mathrm{R}$} & 59 & 1 & $4 \cdot 2$ & $120-132$ & $\mathrm{x}$ & $\mathrm{x}$ & $\mathrm{x}$ \\
\hline & 812 & 1 & $6 \cdot 2$ & 107-131 & $\mathrm{x}$ & $\mathrm{x}$ & $\mathrm{x}$ \\
\hline & $\mathrm{SNP} 2^{\mathrm{b}}$ & & $6 \cdot 9$ & & & $\mathrm{x}$ & $\mathrm{x}$ \\
\hline & 249 & 1 & $8 \cdot 8$ & $108-132$ & $\mathrm{x}$ & $\mathrm{x}$ & $\mathrm{x}$ \\
\hline & $30 \mathrm{C} 1$ & 2 & $9 \cdot 6$ & $155-168$ & $\mathrm{x}$ & $\mathrm{x}$ & $\mathrm{x}$ \\
\hline & $\mathrm{SNP}^{\mathrm{b}}$ & & $10 \cdot 9$ & & $\mathrm{x}$ & $\mathrm{x}$ & $\mathrm{x}$ \\
\hline & 06М19 & 2 & $13 \cdot 1$ & $160-170$ & $\mathrm{x}$ & $\mathrm{x}$ & $\mathrm{x}$ \\
\hline & 119 & 1 & $14 \cdot 8$ & 179-194 & $\mathrm{x}$ & & $\mathrm{x}$ \\
\hline & 555 & 1 & $21 \cdot 3$ & 83-96 & $\mathrm{x}$ & & \\
\hline & 158 & 1 & 22.99 & 78-90 & & & $\mathrm{x}$ \\
\hline & 341 & 1 & $23 \cdot 02$ & 116-142 & & $\mathrm{x}$ & $\mathrm{x}$ \\
\hline & 06H01 & 2 & $25 \cdot 5$ & $127-156$ & $\mathrm{x}$ & $\mathrm{x}$ & $\mathrm{x}$ \\
\hline & $33 \mathrm{C} 1$ & 2 & $25 \cdot 6$ & $147-159$ & & $\mathrm{x}$ & \\
\hline & $06 \mathrm{~F} 05$ & 2 & $31 \cdot 6$ & $174-184$ & & $\mathrm{x}$ & $\mathrm{x}$ \\
\hline & 88 & 1 & $34 \cdot 7$ & 184-197 & & & $\mathrm{x}$ \\
\hline & $30 \mathrm{~L} 17$ & 2 & $41 \cdot 1$ & 71-79 & & $\mathrm{x}$ & $\mathrm{x}$ \\
\hline \multirow[t]{9}{*}{$3 \mathrm{~L}$} & SODI (RFLP) ${ }^{\mathrm{b}}$ & & $5 \cdot 6$ & & & $\mathrm{x}$ & \\
\hline & 811 & 1 & $14 \cdot 8$ & 124-134 & & $\mathrm{x}$ & $\mathrm{x}$ \\
\hline & 577 & 1 & $19 \cdot 8$ & 80-103 & $\mathrm{x}$ & $\mathrm{x}$ & \\
\hline & 817 & 1 & $31 \cdot 9$ & $143-149$ & & $\mathrm{x}$ & $\mathrm{x}$ \\
\hline & $46 \mathrm{C} 2$ & 2 & $41 \cdot 4$ & $177-197$ & & $\mathrm{x}$ & $\mathrm{x}$ \\
\hline & & & \multicolumn{2}{|c|}{ Sum Chromosome x } & $\mathbf{0}$ & 2 & $\mathbf{0}$ \\
\hline & & & \multicolumn{2}{|c|}{ Sum Chromosome 2} & 7 & 10 & 10 \\
\hline & & & \multicolumn{2}{|c|}{ Sum Chromosome 3} & 11 & 18 & 18 \\
\hline & & & & Sum & 18 & 30 & 28 \\
\hline
\end{tabular}

a According to vector base (08/2010).

b SNP markers.

Source: 1, Zheng et al. (1996); 2, Ranson et al. (2004); 3, Witzig et al. (2013).

higher concentration of permethrin $(2 \%)$ and an exposure time of $60 \mathrm{~min}$ resulted in a higher mortality of 46 and $51 \%$ for families 15 and 25 respectively (Table S3 - in Online version only). The total numbers of phenotyped individuals in those families ranged from 43 to 68 mosquitoes. Mortality in females was significantly lower $(P<0 \cdot 05$, MannWhitney $U$ test) than mortality in males in two out of the three families which were exposed to the higher dose of permethrin (Table S3 - in Online version only).

\section{Genotyping of mapping families}

Informative markers were selected on the basis of the genotypes of the parental female $F_{0}$ and eight $F_{1}$ individuals. Informative markers are loci with variation in the genotyped alleles such that at least one of those alleles could be clearly tracked back to one (partially informative) or both (fully informative) of the two parents. Of the 51 microsatellites tested, 34 were fully or partially informative in at least one of the three families, with nine informative in all three 
Table 2. Summary of $\mathrm{F}_{2}$ progeny used for genetic mapping, including number of markers genotyped in each family

\begin{tabular}{|c|c|c|c|c|c|c|c|c|}
\hline \multirow[b]{3}{*}{ Family } & \multicolumn{7}{|c|}{ Number of $F_{2}$ offspring genotyped } & \multirow{3}{*}{$\begin{array}{l}\text { Number of markers } \\
\text { genotyped } \\
\text { (chromosome X, 2, 3) }\end{array}$} \\
\hline & \multicolumn{3}{|l|}{ Dead } & \multicolumn{3}{|l|}{ Alive } & \multirow{2}{*}{$\begin{array}{l}\text { Total } \\
\text { Sum }\end{array}$} & \\
\hline & Sum & 우 & $\hat{0}$ & Sum & 우 & $\hat{0}$ & & \\
\hline 15 & 19 & 6 & 13 & 19 & 6 & 13 & 38 & $18(0,7,11)$ \\
\hline 17 & 16 & 6 & 10 & 47 & 17 & 30 & 63 & $30(2,10,18)$ \\
\hline 25 & 21 & 15 & 6 & 22 & 9 & 13 & 43 & $28(0,10,18)$ \\
\hline Sum & 56 & 27 & 29 & 88 & 32 & 56 & 144 & $76(2,27,47)$ \\
\hline
\end{tabular}

families and 14 informative in two families. Details of the number of markers informative for each family are shown in Table 1.

Three SNPs were identified by de novo sequence analysis (Tables S2 and S3 - in Online version only). These were informative in all families, with the exception of the SNP2 in family 15 . The $1014 k d r$ marker was only informative in family 17 . No alternative SNP marker in the sodium channel was identified in the remaining families.

The three parental $\mathrm{F}_{0}$ females were homozygous for $1014 \mathrm{~F} k d r$ allele. All individuals in families 15 and 25 were homozygous for $k d r(1014 \mathrm{~F})$ whereas individuals of family 17 contained both $1014 \mathrm{~F}$ and $1014 \mathrm{~L}$ alleles $\left(f(1014 \mathrm{~F}) \quad F_{1}=0 \cdot 19 ; \quad f(1014 \mathrm{~F})\right.$ $\left.F_{2}=0 \cdot 35\right)$. The presence of both $1014 \mathrm{~F}$ and $1014 \mathrm{~L}$ alleles in $F_{1}$ of family 17 indicates that the male parent of this line was heterozygote for $k d r$ (as the parental female was confirmed as homozygous for 1014F).

Inversions can interfere with genetic mapping. Hence each family was characterized for the presence of two common inversions, $2 \mathrm{Rb}$ and $2 \mathrm{La}$. All $\mathrm{F}_{0}$ and $\mathrm{F}_{1}$ specimens were homozygous for the inverted $2 \mathrm{Rb}^{+}$arrangement. Both the standard $(\mathrm{S})$ and inverted (I) arrangements of the 2La inversion were present in the $F_{2}$ progeny. Families 15 and 17 show similar frequencies of the standard arrangement with $f(\mathrm{~S})=0.49$ (with $\chi^{2}=0.05$ and $P$ value $=0.82$ ) and $f(\mathrm{~S})=0.47$ (with $\chi^{2}=0.58$ and $P$ value $=0.45$ ) respectively. Family 25 shows values of $f(\mathrm{~S})=0.35$ and $f(\mathrm{I})=0 \cdot 65$ (with $\chi^{2}=1 \cdot 32$ and $P$ value $=0 \cdot 25$ )

\section{Linkage mapping and QTL analysis}

Initially separate linkage maps were generated for each family. Subsequently data from three families (Table 2) were used to build a genetic linkage map containing data from a total of $144 \mathrm{~F}_{2}$ individuals at 76 loci (Fig. 2). The length of the map is $180 \cdot 3 \mathrm{cM}$ with an average resolution of $6.9 \mathrm{cM} /$ marker. Only two informative markers were identified on the $\mathrm{X}$ chromosome and it was not possible to generate a linkage map for this chromosome.
The software Windows QTL cartographer version 2.5 (Wang et al. 2005) was applied to test for linkage between resistance phenotype and genotype using both IM and CIM. IM uses one marker interval at a time to construct a putative QTL for testing by performing a likelihood ratio test at every position in the interval. The IM approach considers one QTL per model, and this can cause problems when multiple QTL are present in one linkage group. CIM is a modification of IM in which additional markers are included as cofactors in the analysis in order to deal with multiple QTL problems (Zheng et al. 1996).

As each family had a different genetic background, and two families were phenotyped using a higher insecticide dose, the results from individual families were first analysed individually (Fig. S1 - in Online version only). One QTL was detected on chromosome $2 \mathrm{~L}$ reaching a $\mathrm{LOD}$ value of $3 \cdot 1$ but only in family 25 and only when using CIM. A second QTL was identified on chromosome $3 \mathrm{R}$ in family 15 . This QTL is detected by both IM and CIM although less pronounced by IM (LOD score of 2.5 vs 1.4 ). The presence of this chromosome 3 QTL in family 15 is supported by the single marker analysis which tests for significant associations between genotype and phenotype. This is plotted in Fig. 1 which shows mortality rate as a function of the number of alleles inherited from the resistant parent.

The data for all three families were then combined and CIM and IM repeated. Two clear QTLs were readily identifiable using both methodologies (Fig. 2). The QTL on chromosome $2 \mathrm{~L}$ and chromosome 3R had associated LOD scores of $2 \cdot 5$ and $2 \cdot 0$, respectively using CIM. MIM also predicted the two QTLs, which together account for $13 \cdot 2 \%$ of the genotypic variance for the combined data set (Table 3).

\section{DISCUSSION}

This study identified two potential QTL associated with permethrin resistance in M form $A$. gambiae s.s. from southern Benin. The first of these is located on chromosome 2 and spans the genomic region 


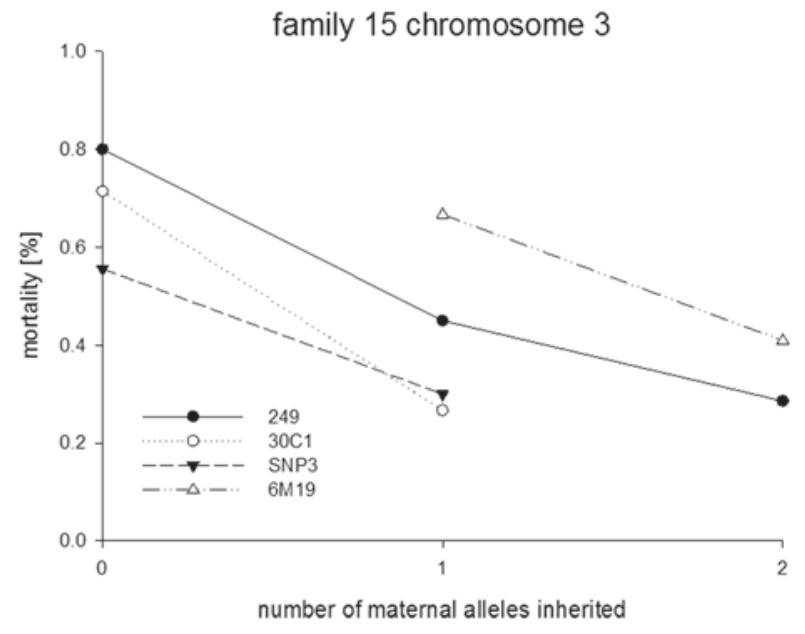

Fig. 1. Mortality rate as a function of alleles inherited from the resistant parent (maternal) for markers on chromosome $3 \mathrm{R}$ for family 15 showing significant phenotype: genotype association.

encoding the major pyrethroid target site, the voltage-gated sodium channel. Two of the three families were fixed for the $1014 \mathrm{~F} k d r$ allele itself and no further SNPs to add additional genotyping information could be identified within this gene to enable the linkage between the target site and this QTL to be assessed. The vicinity of the centromere and the heterogeneity in the 2La karyotype, may have both contributed to a reduced recombination in this region of the genome. Finer scale mapping in this region was impeded by the lack of informative markers that were identified on chromosome $2 \mathrm{~L}$. Hence at this stage it can only be postulated that the chromosome 2 QTL equates to target site resistance.

The second putative QTL is located on chromosome 3R spanning chromosomal division 30A-D. Chromosome $3 \mathrm{R}$ is densely clustered with detoxification genes and $18 \mathrm{P} 450$ genes are located within the boundaries of this QTL, including Cyp6m2, identified as a candidate resistance gene in microarray experiments (Djouaka et al. 2008; Müller et al. 2008; Mitchell et al. 2012) and $C y p 6 z 1$ and $C y p 6 z 2$, which have been found associated with pyrethroid resistance in other colonies (Nikou et al. 2003; David et al. 2005; Müller et al. 2007). In addition 12 of the 27 Cplcg genes (cuticular proteins with low-sequence complexity) in A. gambiae are found clustered within division 30D on chromosome 3R (Willis, 2010). Overexpression of cuticular proteins causing reduced cuticular penetration of insecticides has been implicated in insecticide resistance (Puinean et al. 2010). Two of the genes in this cluster, Cplcg3 and Cplcg4, were found over expressed in resistant populations from southern Benin (Djouaka et al. 2008). Determining the precise nature of the chromosome 3R QTL will require fine-scale mapping on advanced intercross lines followed by functional characterization of candidate genes (Wondji et al. 2009).
QTL analysis of the $\mathrm{X}$ chromosome was not possible as only two informative markers were identified on this chromosome. Based on a smaller effective population size the average level of polymorphism on the $\mathrm{X}$ chromosome is reduced (Holt et al. 2002) making identification of informative markers very difficult. The absence of a QTL on $2 \mathrm{R}$ around the candidate gene $C y p 6 p 3$ which was previously found to be highly overexpressed in this population could be due to the limitations in the study, such as small number of families tested in this experiment or due to the lack of sufficient markers around this region. Alternatively, it may indicate that over expression of this $\mathrm{P} 450$ is under the control of a trans regulator.

Interestingly, there are parallels between the results of the current study, and previous QTL mapping studies of permethrin resistance using laboratory colonies originating from East Africa (Ranson et al. 2004). Both studies identified two QTL with similar boundaries, and in both the chromosome 3R QTL spans chromosomal divisions 30A-30C, encompassing several large clusters of $\mathrm{P} 450$ genes. However, given the inherent imprecision in genetic mapping studies on $\mathrm{F}_{2}$ generations, it would be premature to conclude that the QTL identified in the Kenyan and Benin study equate to the same genetic factor.

\section{Limitations of the study design}

The current study was limited in its ability to precisely map QTL by the lack of informative markers, the numbers of available families and progeny, and difficulties in scoring the phenotype.

Heterogeneity at the $2 \mathrm{La}$ inversion may have restricted the mapping resolution in this region by suppressing recombination (Butlin, 2005). Previous genetic mapping studies on permethrin resistance in A. gambiae used a laboratory strain (RSP-ST) fixed for the 2La standard chromosomal arrangement to overcome this limitation (Ranson et al. 2004). However, it is also possible that variation was restricted by selective sweep surrounding the $k d r$ locus, as has been detected in outbred wild populations (Lynd et al. 2010). The $1014 \mathrm{~F} k d r$ locus is present at very high frequency in Southern Benin, and five of the six parents from the three isofemale lines used in the current study were fixed for this resistance allele reducing the variation among families in this part of chromosome 2 .

To improve the study design presented, increasing the size of the mapping populations, either by using advanced intercross lines to increase both the sample size and number of recombination events is recommended. Pooling data of single families increased the mapping resolution of the QTL study only marginally from $7 \cdot 1$ to $6 \cdot 9 \mathrm{cM} /$ marker. But pooling 
Table 3. MIM estimates of QTL position and associated genetic variance associated with permethrin survival QTL in A. gambiae

\begin{tabular}{|c|c|c|c|c|c|}
\hline & $\sigma \mathrm{g} 2[\%]$ & $\begin{array}{l}\sigma \mathrm{g} 2[\%] \\
\text { per locus }\end{array}$ & $\begin{array}{l}\text { Nearest } \\
\text { marker }\end{array}$ & $¥$ & $\begin{array}{l}\text { Genetic } \\
\text { distance } \\
{[\mathrm{cM}]}\end{array}$ \\
\hline \multicolumn{6}{|l|}{$\begin{array}{l}\text { Combined all } \\
\text { families }\end{array}$} \\
\hline & $13 \cdot 2$ & $\begin{array}{l}56 \\
44\end{array}$ & $\begin{array}{l}117 * \\
249\end{array}$ & $\begin{array}{l}2 \mathrm{R}^{\mathrm{a}} \\
3 \mathrm{R}\end{array}$ & $\begin{array}{l}54 \cdot 3 \\
18 \cdot 3\end{array}$ \\
\hline
\end{tabular}

$\sigma \mathrm{g} 2[\%]$ genetic variance in $\%$ of overall estimated phenotypic variance and per locus.

$¥$ Chromosome and location in genetic distance for nearest marker.

a Associated marker located on chromosome $2 \mathrm{R}$, but effect possibly due to $k d r$ on $2 \mathrm{~L}$.

\section{Chromosome 2}

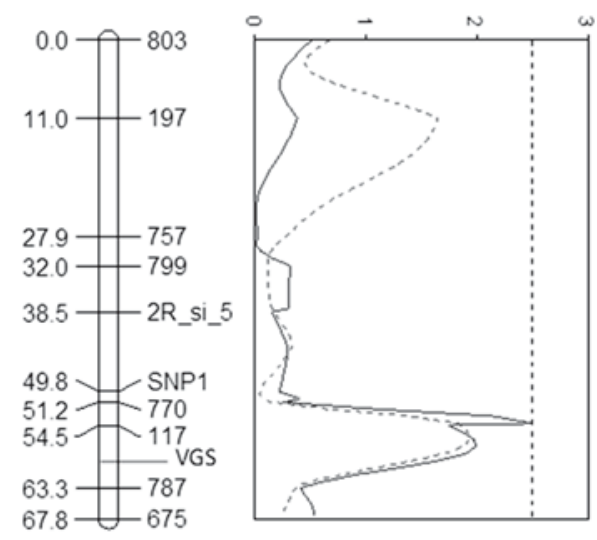

\section{Chromosome 3}

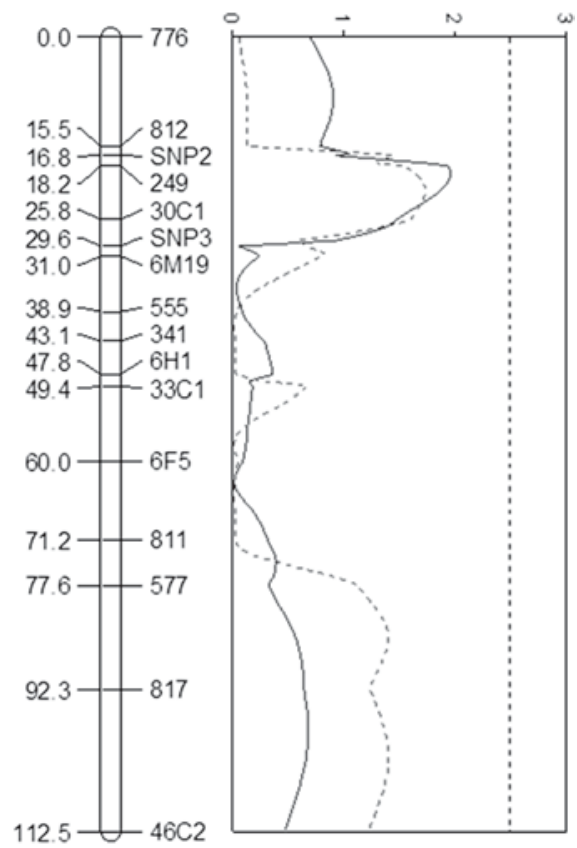

Fig. 2. LOD plots and genetic linkage maps using the combined data from the three families. The location of the voltage-gated sodium channel is indicated (VGS) based on its physical location between markers 117 and 787 . A scale of genetic distance in centimorgans is shown on the left; the names of the genetic markers are given on the right. Plot of LOD scores estimated by IM (dashed) and CIM (solid) for all three families. The dotted line represents a LOD score of $2 \cdot 5$, typically used as a cut off for significance (Lander and Botstein, 1989).

may not always be advisable as there is a danger that it may mask rare QTLs. Increasing the number of families analysed may be advantageous, yet more families will not replace the need for a larger sample size within analysed families.

Further limitations were imposed by the phenotyping method adopted. Insecticide resistance is a quantitative trait yet by scoring only two outcomes after exposure to insecticides, alive or dead, the quantitative data are reduced to a binary trait. Scoring extreme phenotypes only, by using a range of exposure times, would have increased the power but still not converted this to a quantitative measurement. Other approaches, such as recording time to kill, were discarded as insecticides may not result in immediate lethality.

All previous QTL mapping studies in malaria vectors have utilized experimental crosses between two inbred laboratory strains of mosquitoes, a resistant and a susceptible population (Ranson et al. 2000b, 2004; Wondji et al. 2007b, 2009; SaavedraRodriguez et al. 2008) and usually these strains have been maintained under laboratory insecticide selection pressure for multiple generations prior to the establishment of the genetic crosses. Although this has several logistical advantages over the use of 
natural pedigrees, foremost of which is the ease with which additional families can be added to the study to enhance the resolution, there are also some considerable limitations. Some resistance alleles may prove unstable under laboratory conditions, being rapidly lost in colonies. This may be attributable to fitness costs associated with these resistance alleles or may simply be a result of genetic drift caused by bottlenecks that inevitably occur when adapting a mosquito population to insectary conditions. Furthermore, maintaining a laboratory colony under selection with insecticides may result in a phenotype that differs greatly from that found in natural populations. Theory suggests that laboratory selection for resistance preferentially selects for resistance factors of minor effects such as body size and developmental rate whereas selection in the field, which generally involves exposure to much higher concentrations, favours the selection of rare mutations with major effect (Ffrench-Constant et al. 2004). As a result, QTL studies using this design may be trying to establish genotype-phenotype associations based on a genetic make-up that is very unlikely to exist in field populations (Dworkin et al. 2005). A hybrid of these two approaches has recently been applied to identify the major loci associated with pyrethroid resistance in A. arabiensis from Chad. In this experiment, the mapping population was generated by crossing a laboratory susceptible colony with the $F_{1}$ generation from field collections of a resistant population. Establishing laboratory crosses reduced the restrictions imposed by limited fecundity and/or survivorship of natural pedigrees but also minimized the danger of loss of resistance alleles and/or selection or atypical alleles that results from prolonged laboratory colonization and selection (Witzig et al. 2013).

\section{CONCLUSION}

This study indicates the presence of two QTL associated with resistance to permethrin in natural pedigrees of $A$. gambiae $\mathrm{M}$ form from Benin. Similarities were identified with the QTLs detected in a laboratory pyrethroid-resistant strain originating from Kenya but until the boundaries of these QTL can be reduced it is premature to speculate whether they do indeed map to the same genetic factors. Intriguingly, results from microarray comparisons of transcripts overexpressed in pyrethroid-resistant and -susceptible strains across Africa are converging on a small number of candidate cytochrome P450 genes. Whether the QTLs identified in the mapping studies are responsible for oxidase based metabolic resistance in A. gambiae is currently unknown. Ongoing studies involving next generation sequencing of multiple pyrethroid resistant $A$. gambiae populations from across Africa may help to address this question.
FINANCIAL SUPPORT

C.S.W. is supported by a Wellcome Trust Research Career Development Fellowship.

\section{REFERENCES}

Awolola, T. S., Oduola, O. A., Strode, C., Koekemoer, L. L., Brooke, B. and Ranson, H. (2009). Evidence of multiple pyrethroid resistance mechanisms in the malaria vector Anopheles gambiae sensu stricto from Nigeria. Transactions of the Royal Society of Tropical Medicine and Hygiene 103, 1139-1145.

Barrett, J. C., Fry, B., Maller, J. and Daly, M. J. (2005). Haploview: analysis and visualization of LD and haplotype maps. Bioinformatics 21, 263-265.

Butlin, R. K. (2005). Recombination and speciation. Molecular Ecology 14, 2621-2635.

Collins, F.H., Mendez, M. A., Rasmussen, M. O., Mehaffey, P.C., Besansky, N. J. and Finnerty, V. (1987). A ribosomal RNA gene probe differentiates member species of the Anopheles gambiae complex. American Fournal of Tropical Medicine and Hygiene 37, 37-41.

Constant, E. A. V., Koudou, B. G., Jones, C. M., Weetman, D. and Ranson, H. (2012). Resistance to all insecticide classes available for malaria control in a population of Anopheles gambiae from southern Côte d'Ivoire. Emerging Infectious Diseases 18, 1508.

David, J.-P., Strode, C., Vontas, J., Nikou, D., Vaughan, A., Pignatelli, P. M., Louis, C., Hemingway, J. and Ranson, H. (2005). The Anopheles gambiae detoxification chip: a highly specific microarray to study metabolic-based insecticide resistance in malaria vectors. Proceedings of the National Academy of Sciences, USA 102, 4080-4084.

Djègbè, I., Boussari, O., Sidick, A., Martin, T., Ranson, H., Chandre, F., Akogbéto, M. and Corbel, V. (2011). Dynamics of insecticide resistance in malaria vectors in Benin: first evidence of the presence of L1014S kdr mutation in Anopheles gambiae from West Africa. Malaria fournal 10, 1-11.

Djouaka, R., Bakare, A., Coulibaly, O., Akogbeto, M., Ranson, H., Hemingway, J. and Strode, C. (2008). Expression of the cytochrome P450s, CYP6P3 and CYP6M2 are significantly elevated in multiple pyrethroid resistant populations of Anopheles gambiae s.s. from Southern Benin and Nigeria. BMC Genomics 9, 538.

Dworkin, I., Palsson, A. and Gibson, G. (2005). Replication of an Egfrwing shape association in a wild-caught cohort of Drosophila melanogaster. Genetics 169, 2115-2125.

Ffrench-Constant, R. H., Daborn, P. J. and Le Goff, G. (2004). The genetics and genomics of insecticide resistance. Trends in Genetics: TIG 20, $163-170$.

Gillies, M. T. and de Meillon, B. (1968). The Anophelinae of Africa south of the Sahara (Ethiopian Zoogeographical Region), 2nd Edn. South African Institute for Medical Research, Johannesburg.

Heckel, D. G. (1993). Comparative genetic linkage mapping in insects. Annual Review of Entomology 38, 381-408.

Holt, R. A., Subramanian, G. M., Halpern, A., Sutton, G. G., Charlab, R., Nusskern, D. R., Wincker, P., Clark, A. G., Ribeiro, J. M. C., Wides, R., Salzberg, S. L., Loftus, B., Yandell, M., Majoros, W. H., Rusch, D. B., Lai, Z., Kraft, C. L., Abril, J. F., Anthouard, V., Arensburger, P., Atkinson, P.W., Baden, H., de Berardinis, V., Baldwin, D., Benes, V., Biedler, J., Blass, C., Bolanos, R., Boscus, D., Barnstead, M., Cai, S., Center, A., Chatuverdi, K., Christophides, G. K., Chrystal, M. A., Clamp, M., Cravchik, A., Curwen, V., Dana, A., Delcher, A., Dew, I., Evans, C. A., Flanigan, M., Grundschober-Freimoser, A., Friedli, L., Gu, Z., Guan, P., Guigo, R., Hillenmeyer, M. E., Hladun, S. L., Hogan, J. R., Hong, Y.S., Hoover, J., Jaillon, O., Ke, Z., Kodira, C., Kokoza, E., Koutsos, A., Letunic, I., Levitsky, A., Liang, Y., Lin, J.-J., Lobo, N. F., Lopez, J. R., Malek, J. A., McIntosh, T. C., Meister, S., Miller, J., Mobarry, C., Mongin, E., Murphy, S. D., O’Brochta, D. A., Pfannkoch, C., Qi, R., Regier, M. A., Remington, K., Shao, H., Sharakhova, M. V., Sitter, C. D., Shetty, J., Smith, T. J., Strong, R., Sun, J., Thomasova, D., Ton, L. Q., Topalis, P., Tu, Z., Unger, M. F., Walenz, B., Wang, A., Wang, J., Wang, M., Wang, X., Woodford, K. J., Wortman, J. R., Wu, M., Yao, A., Zdobnov, E. M., Zhang, H., Zhao, Q., Zhao, S., Zhu, S. C., Zhimulev, I., Coluzzi, M., della Torre, A., Roth, C. W., Louis, C., Kalush, F., Mural, R. J., Myers, E.W., Adams, M. D., Smith, H. O., Broder, S., Gardner, M. J. Fraser, C. M., Birney, E., Bork, P., Brey, P. T., Venter, J.C., Weissenbach, J., Kafatos, F. C., Collins, F.H. and Hoffman, S. L. (2002). The genome sequence of the malaria mosquito Anopheles gambiae. Science 298, 129-149. 
Jansen, R. C. (1993). Interval mapping of multiple quantitative trait loci. Genetics 135, 205-211.

Jones, C. M., Liyanapathirana, M., Agossa, F. R., Weetman, D. Ranson, H., Donnelly, M. J. and Wilding, C. S. (2012). Footprints of positive selection associated with a mutation $(\mathrm{N} 1575 \mathrm{Y})$ in the voltage-gated sodium channel of Anopheles gambiae. Proceedings of the National Academy of Sciences, USA 109, 6614-6619.

Kao, C.-H., Zeng, Z.-B. and Teasdale, R. D. (1999). Multiple interval mapping for quantitative trait loci. Genetics 152, 1203-1216.

Knipple, D. C., Doyle, K. E., Marsella-Herrick, P.A. and Soderlund, D. M. (1994). Tight genetic linkage between the $k d r$ insecticide resistance trait and a voltage-sensitive sodium channel gene in the house fly. Proceedings of the National Academy of Sciences, USA 91, 2483-2487.

Lander, E. S. and Botstein, D. (1989). Mapping mendelian factors underlying quantitative traits using RFLP linkage maps. Genetics 121 185-199.

Lawniczak, M. K. N., Emrich, S. J., Holloway, A. K., Regier, A.P., Olson, M., White, B., Redmond, S., Fulton, L., Appelbaum, E., Godfrey, J., Farmer, C., Chinwalla, A., Yang, S. P., Minx, P., Nelson, J., Kyung, K., Walenz, B.P., Garcia-Hernandez, E., Aguiar, M., Viswanathan, L.D., Rogers, Y.H., Strausberg, R. L., Saski, C. A., Lawson, D., Collins, F.H., Kafatos, F. C., Christophides, G. K., Clifton, S.W., Kirkness, E. F. and Besansky, N. J. (2010). Widespread divergence between incipient Anopheles gambiae species revealed by whole genome sequences. Science 330, 512-514.

Lobo, N., Sangare, D., Regier, A., Reidenbach, K., Bretz, D. Sharakhova, M., Emrich, S., Traore, S., Costantini, C., Besansky, N. and Collins, F. (2010). Breakpoint structure of the Anopheles gambiae 2Rb chromosomal inversion. Malaria fournal 9, 293.

Lowry, R. (2004). VassarStats: Website for Statistical Computation, Vassar College. http://vassarstats.net/

Lynd, A., Weetman, D., Barbosa, S., Egyir Yawson, A., Mitchell, S., Pinto, J., Hastings, I. and Donnelly, M. J. (2010). Field, genetic, and modeling approaches show strong positive selection acting upon an insecticide resistance mutation in Anopheles gambiae s.s. Molecular Biology and Evolution 27, 1117-1125.

Martinez-Torres, D., Chandre, F., Williamson, M. S., Darriet, F., Berge, J. B., Devonshire, A. L., Guillet, P., Pasteur, N. and Pauron, D. (1998). Molecular characterization of pyrethroid knockdown resistance ( $k d r)$ in the major malaria vector Anopheles gambiae s.s. Insect Molecular Biology 7, 179-184.

Megy, K., Emrich, S. J., Lawson, D., Campbell, D., Dialynas, E., Hughes, D. S. T., Koscielny, G., Louis, C., MacCallum, R. M., Redmond, S. N., Sheehan, A., Topalis, P., Wilson, D. and Consortium, T. V. (2012). VectorBase: improvements to a bioin formatics resource for invetebrate vector genomics. Nucleic Acids Research 40 D729-D734

Milani, R. (1963). Genetical aspects of insecticide resistance. Bulletin of the World Health Organization 29, 77-87.

Mitchell, S. N., Stevenson, B. J., Müller, P., Wilding, C. S. Egyir-Yawson, A., Field, S. G., Hemingway, J., Paine, M. J. I., Ranson, H. and Donnelly, M. J. (2012). Identification and validation of a gene causing cross-resistance between insecticide classes in Anopheles gambiae from Ghana. Proceedings of the National Academy of Sciences, USA 109, 6147-6152.

Morgan, J. C., Irving, H., Okedi, L. M., Steven, A. and Wondji, C.S. (2010). Pyrethroid resistance in an Anopheles funestus population from Uganda. PLoS ONE 5, e11872.

Müller, P., Donnelly, M. and Ranson, H. (2007). Transcription profiling of a recently colonised pyrethroid resistant Anopheles gambiae strain from Ghana. BMC Genomics 8, 36

Müller, P., Warr, E., Stevenson, B. J., Pignatelli, P. M., Morgan, J. C., Steven, A., Yawson, A.E., Mitchell, S. N., Ranson, H., Hemingway, J., Paine, M. J. I. and Donnelly, M. J. (2008). Field-caught permethrin-resistant Anopheles gambiae overexpress $C Y P 6 P 3$, a $\mathrm{P} 450$ that metabolises pyrethroids. PLoS Genetics 4, e1000286.

Neafsey, D. E., Lawniczak, M. K. N., Park, D. J., Redmond, S. N., Coulibaly, M. B., Traoré, S. F., Sagnon, N., Costantini, C., Johnson, C., Wiegand, R.C., Collins, F.H., Lander, E.S., Wirth, D.F., Kafatos, F. C., Besansky, N.J., Christophides, G.K. and Muskavitch, M. A. T. (2010). SNP genotyping defines complex geneflow boundaries among African malaria vector mosquitoes. Science 330, 514-517.

Niare, O., Markianos, K., Volz, J., Oduol, F., Toure, A., Bagayoko, M. Sangare, D., Traore, S. F., Wang, R., Blass, C., Dolo, G., Bouare, M., Kafatos, F. C., Kruglyak, L., Toure, Y. T. and Vernick, K. D. (2002)
Genetic loci affecting resistance to human malaria parasites in a West African mosquito vector population. Science 298, 213-216.

Nikou, D., Ranson, H. and Hemingway, J. (2003). An adult-specific CYP6 P450 gene is overexpressed in a pyrethroid-resistant strain of the malaria vector, Anopheles gambiae. Gene 318, 91-102.

Oetting, W.S., Armstrong, C. M., Ronan, S. M., Young, T. L. Sellers, T. A. and King, R. A. (1998). Multiplexed short tandem repeat polymorphisms of the Weber $8 \mathrm{~A}$ set of markers using tailed primers and infrared fluorescence detection. Electrophoresis 19, 3079-3083.

Plapp, F. W. (1976). Biochemical genetics of insecticide resistance. Annual Review of Entomology 21, 179-197.

Puinean, A. M., Foster, S. P., Oliphant, L., Denholm, I., Field, L. M., Millar, N.S., Williamson, M.S. and Bass, C. (2010). Amplification of a cytochrome $\mathrm{P} 450$ gene is associated with resistance to neonicotinoid insecticides in the aphid Myzus persicae. PLoS Genetics 6, e1000999.

Ranson, H., Abdallah, H., Badolo, A., Guelbeogo, W. M., Kerah-Hinzoumbé, C., Yangalbé-Kalnoné, E., Sagnon, N., Simard, F. and Coetzee, M. (2009). Insecticide resistance in Anopheles gambiae: data from the first year of a multi-country study highlight the extent of the problem. Malaria fournal 8, 299.

Ranson, H., Jensen, B., Vulule, J. M., Wang, X., Hemingway, J. and Collins, F.H. $(2000 a)$. Identification of a point mutation in the voltage-gated sodium channel gene of Kenyan Anopheles gambiae associated with resistance to DDT and pyrethroids. Insect Molecular Biology 9, 491-497.

Ranson, H., Jensen, B., Wang, X., Prapanthadara, L., Hemingway, J. and Collins, F. H. $(2000 \mathrm{~b})$. Genetic mapping of two loci affecting DDT resistance in the malaria vector Anopheles gambiae. Insect Molecular Biology 9, 499-507.

Ranson, H., Paton, M. G., Jensen, B., McCarroll, L., Vaughan, A., Hogan, J. R., Hemingway, J. and Collins, F. H. (2004). Genetic mapping of genes conferring permethrin resistance in the malaria vector, Anopheles gambiae. Insect Molecular Biology 13, 379-386.

Reimer, L., Fondjo, E., Patchoke, S., Diallo, B., Lee, Y., Ng, A., Ndjemai, H. M., Atangana, J., Traore, S. F., Lanzaro, G. and Cornel, A. J. (2008). Relationship between $k d r$ mutation and resistance to pyrethroid and DDT insecticides in natural populations of Anopheles gambiae. Fournal of Medical Entomology 45, 260-266.

Riehle, M. M., Markianos, K., Niare, O., Xu, J., Li, J., Toure, A. M., Podiougou, B., Oduol, F., Diawara, S., Diallo, M., Coulibaly, B. Ouatara, A., Kruglyak, L., Traore, S. F. and Vernick, K. D. (2006). Natural malaria infection in Anopheles gambiae is regulated by a single genomic control region. Science 312, 577-579.

Saavedra-Rodriguez, K. L., Strode, C., Flores Suarez, A., Fernandez Salas, I., Ranson, H., Hemingway, J. and Black, W. C. (2008). QTL mapping of genome regions controlling permethrin resistance in the mosquito Aedes aegypti. Genetics 180, 1137-1152.

Santolamazza, F., Mancini, E., Simard, F., Qi, Y., Tu, Z. and della Torre, A. (2008). Insertion polymorphisms of SINE200 retrotransposons within speciation islands of Anopheles gambiae molecular forms. Malaria Fournal 7, 163.

Stam, R. and van Ooijen, J. W. (1996). FoinMap (TM) Version 2.0: Software for the Calculation of Genetic Linkage Maps. CPRO-DLO, Wageningen

Stevenson, B. J., Bibby, J., Pignatelli, P., Muangnoicharoen, S., O’Neill, P. M., Lian, L.-Y., Müller, P., Nikou, D., Steven, A., Hemingway, J., Sutcliffe, M. J. and Paine, M. J. I. (2011). Cytochrome P450 6M2 from the malaria vector Anopheles gambiae metabolizes pyrethroids: sequential metabolism of deltamethrin revealed. Insect Biochemistry and Molecular Biology 41, 492-502.

Wang, S., Basten, C. and Zeng, Z. (2005). Windows QTL Cartographer 2.5. Department of Statistics, North Carolina State University, Raleigh, NC.

Weetman, D., Wilding, C. S., Steen, K., Morgan, J. C., Simard, F. and Donnelly, M. J. (2010). Association mapping of insecticide resistance in wild Anopheles gambiae populations: major variants identified in a lowlinkage disequilbrium genome. PLoS ONE 5, e13140.

White, B. J., Santalomazza, F., Kamau, L., Pombi, M., Grushko, O., Mouline, K., Brengues, C., Guelbeogo, W., Coulibaly, M., Kayondo, J. K., Sharakhov, I., Simard, F., Petrarca, V., Della Torre, A. and Besansky, N. J. (2007). Molecular karyotyping of the $2 \mathrm{La}$ inversion in Anopheles gambiae. American fournal of Tropical Medicine and Hygiene 76, 334-339.

WHO (1998). Test Procedures for Insecticide Resistance Monitoring in Malaria Vectors, Bio-efficacy and Persistence of Insecticides on Treated Surfaces: Report of the WHO Informal Consultation. World Health Organization, Geneva. 
WHO (2011). World Malaria Report 2011. World Health Organization, Geneva

WHO (2012). Global Plan for Insecticide Resistance Management in Malaria vectors (GPIRM). World Health Organization, Geneva

Williamson, M.S., Denholm, I., Bell, C. A. and Devonshire, A. L. (1993). Knockdown resistance $(k d r)$ to DDT and pyrethroid insecticides maps to a sodium channel gene locus in the housefly (Musca domestica). Molecular and General Genetics 240, 17-22.

Willis, J.H. (2010). Structural cuticular proteins from arthropods: annotation, nomenclature, and sequence characteristics in the genomics era. Insect Biochemistry and Molecular Biology 40, 189-204.

Witzig, C., Parry, M., Morgan, J. C., Irving, H., Steven, A., Cuamba, N., Kerah-Hinzoumbé, C., Ranson, H. and Wondji, C.S. (2013). Genetic mapping identifies a major locus spanning P450 clusters associated with pyrethroid resistance in $\mathrm{kdr}$-free Anopheles arabiensis from Chad. Heredity, in press.

Wondji, C. S., Hemingway, J. and Ranson, H. (2007a). Identification and analysis of single nucleotide polymorphisms (SNPs) in the mosquito Anopheles funestus, malaria vector. BMC Genomics $\mathbf{8}$.

Wondji, C.S., Morgan, J., Coetzee, M., Hunt, R.H., Steen, K., Black, W. C., Hemingway, J. and Ranson, H. (2007b). Mapping a quantitative trait locus (QTL) conferring pyrethroid resistance in the African malaria vector Anopheles funestus. BMC Genomics 8, 34 .

Wondji, C.S., Irving, H., Morgan, J., Lobo, N.F., Collins, F. H., Hunt, R. H., Coetzee, M., Hemingway, J. and Ranson, H. (2009). Two duplicated P450 genes are associated with pyrethroid resistance in Anopheles funestus, a major malaria vector. Genome Research 19, 452-459.

Yadouleton, A., Padonou, G., Asidi, A., Moiroux, N., Bio-Banganna, S., Corbel, V., N'Guessan, R., Gbenou, D., Yacoubou, I., Gazard, K. and Akogbeto, M. (2010). Insecticide resistance status in Anopheles gambiae in southern Benin. Malaria Fournal 9,83.

Zeng, Z.-B. (1993). Theoretical basis for separation of multiple linked gene effects in mapping quantitative trait loci. Proceedings of the National Academy of Sciences, USA 90, 10972-10976.

Zheng, L., Benedict, M. Q., Cornel, A. J., Collins, F.H. and Kafatos, F. C. (1996). An integrated genetic map of the African human malaria vector mosquito, Anopheles gambiae. Genetics 143, 941-952.

Zheng, L., Cornel, A. J., Wang, R., Erfle, H., Voss, H., Ansorge, W., Kafatos, F.C. and Collins, F.H. (1997). Quantitative Trait Loci for refractoriness of Anopheles gambiae to Plasmodium cynomolgi B. Science 276, $425-428$. 